\title{
EFFECT OF WELD STRENGTH MISMATCH AND WELD WIDTH ON THE FRACTURE TOUGHNESS DETERMINED FROM SENB SPECIMENS
}

\author{
Philippa L. Moore \\ TWI Ltd \\ Great Abington, \\ Cambridge, CB21 6AL, UK \\ Tel: +44 (0)1223899000, \\ philippa.moore@twi.co.uk
}

\author{
Natalia Garban \\ TWI Ltd \\ Great Abington, \\ Cambridge, CB21 6AL, UK \\ Tel: +44 (0)1223899000, \\ natalia.garban@twi.co.uk
}

\author{
Philippe Bastid \\ TWI Ltd \\ Great Abington, Cambridge, \\ CB21 6AL, UK \\ Tel: +44 (0)1223899000, \\ philippe.bastid@twi.co.uk
}

\author{
Kevin Hughes \\ Brunel University/NSIRC \\ Great Abington, \\ Cambridge, CB21 6AL, UK \\ Tel: +44 (0)1223 940107 \\ kevin.hughes@brunel.ac.uk
}

\section{ABSTRACT}

In fracture toughness test standard BS EN ISO 15653 for weld and HAZ specimens, there is limited guidance about how the weld width, and the weld metal to parent yield strength mismatch ratio can affect the fracture toughness of materials, nor how to interpret the results should these parameters fall outside the permitted limits given in the Standard. This research was carried out to evaluate how the values of $\mathbf{J}$ determined from fracture toughness test results are affected by the weld width and weld strength mismatch, by using FEA models of single edge notched bend (SENB) specimens.

Fracture toughness results from specimens notched into the weld centreline, of different mismatch ratios and weld widths, are compared with homogeneous materials specimens. The results show that for any mismatch ratio, fracture toughness for welds wider than $20 \mathrm{~mm}$ are similar to homogeneous material. However, the fracture toughness decreases as the weld become narrower than $20 \mathrm{~mm}$. When this variation is taken as a percentage between a homogeneous material and a welded specimen, $\mathrm{J}$ varies for each weld width following the same trend for a specific mismatch ratio, independently of the material strength. To enable prediction of the fracture toughness behaviour of welded specimens, equations have been developed for comparison to homogeneous weld metal or homogeneous parent metal, as a function of the weld mismatch ratio and the weld width.

The real question is whether the Standard methods can nonetheless determine weld metal fracture toughness accurately in overmatched welds of different widths. From comparisons of $\mathbf{J}$ values extracted directly from the contour integral, and $\mathbf{J}$ values calculated using the standard equation (but based on loadCMOD data), it was found that standard methods vary by less

than $5 \%$ in the majority of the cases. The exception was for the combination of mismatch ratio above 1.46 and welds narrower than $20 \mathrm{~mm}$. Therefore, it could be said that the Standard BS EN ISO 15653 is conservative with the overestimation percentage of $10 \%$, since all model cases within the Standard limits of mismatch of 1.5 , the largest over-estimation was only $6 \%$, and typically less than $4 \%$.

\section{INTRODUCTION}

\subsection{How weld properties are accounted for in current standards}

The fracture toughness characterisation of welds and heataffected zones is described in standard BS EN ISO 15653 [1]. The Standard recognises that the presence of weld metal, with potentially very different yield strength to the parent metal, can affect the value of fracture toughness obtained. In section 12 of the Standard (describing post-test analysis) certain limitations and advice are given when interpreting the results. Specifically, clause 12.4.2 regarding the permissible level of weld strength overmatch and the weld width when calculating J and CTOD, states that the test specimen should meet the following requirements for the value of fracture toughness to be qualified [1].

"For calculating CTOD in weld metal tests:

1. If the crack is in the centre of the weld, the ratio of the weld width (over the central $75 \%$ of the thickness) to the crack ligament length shall be greater than 0,2.

2. If the crack is offset from the weld centreline, the ratio of the effective weld width (shortest distance between the crack plane and the weld fusion boundary over the central $75 \%$ of 
the specimen thickness) to the crack ligament length shall be greater than 0,1 .

3. The ratio of the weld metal $0,2 \%$ offset yield strength to the parent metal 0,2\% offset yield strength shall be in the range 0,50 to 1,50 .

For estimating $J$ in weld metal tests: The ratio of weld metal to parent metal 0,2\% offset yield strengths is in the range 0,50 to 1,25."

When the strength mismatch is greater than that stated (over 1.50 for CTOD and over 1.25 for $\mathrm{J}$ ), it is explained that the fracture toughness is overestimated. On the other hand, if the strength mismatch is below 0.5 there is an underestimation. The estimations when mismatch is within the given limits may result in $\pm 10 \%$ error in weld metal CTOD or J.

The limits given in these clauses are based on research from the 1990s [2], and these clauses do not provide guidance on how users could expect weld widths beyond the limits given in the standard to affect the value of fracture toughness. Some more recent research on the effect of weld strength mismatch was published by Donato et al in 2009 [3]. This paper presents an upto-date review of these clauses given on the restrictions of weld strength over-matching and weld width on the values of $\mathbf{J}$ and CTOD obtained, with a view to providing additional guidance in future versions of BS EN ISO 15653.

\subsection{Typical weld dimensions and strength mismatch ratios}

In order to focus the scope of the investigation and modelling, materials properties, material thickness and weld widths were based on those commonly experienced in high integrity steel structures. The lowest strength commercial weld consumable (ER 70S-6) has a yield strength of around $520 \mathrm{MPa}$ [4], which could be used to weld mild steels with as low as $275 \mathrm{MPa}$ specified yield strength. Therefore the mismatch ratio $\left(\mathrm{M}_{\mathrm{y}}\right)$ range considered in this work was based on a fixed weld metal strength and a range of parent metal grades, giving $\mathrm{M}_{\mathrm{y}}$ between 1 and 1.89. Most codes and specifications require the yield strength of the weld metal to exceed that of the parent plate (strength overmatching). This means that under high loads, global structural yielding would occur in the parent steel, shielding the weld metal (and the most likely location of flaws) from the highest stresses and strains.

The weld width can be affected by the joint design and the welding process. For instance, electron beam welds can be as narrow as 3-5mm; narrow-gap gas metal arc welds (GMAW) are often around $10-15 \mathrm{~mm}$ wide; while conventional GMAW and submerged arc welds (SAW) could be up to $40 \mathrm{~mm}$ (or more) wide depending on material thickness and joint geometry. In this study, steel with a plate thickness of $20 \mathrm{~mm}$ was chosen to cover typical materials for oil \& gas, power, structural and defence type applications to have widest application.

\section{NUMERICAL MODELLING OF SENB SPECIMENS CONTAINING WELDS \\ 2.1 Validation of the SENB numerical modelling approach}

A numerical model of a single edge notched bend (SENB) fracture toughness test specimen was developed, by reproducing the dimension of an actual experimental test specimen. The model response could then be validated against the measured load and displacement from the experiment. The validation case was a parent steel specimen with a yield strength of 420MPa and a UTS of 585MPa, with a full stress-strain curve based on tensile test data was used for the model. The specimen was $\mathrm{B} \times 2 \mathrm{~B}$ (rectangular) cross section geometry of $20 \mathrm{~mm} \times 40 \mathrm{~mm}$, with an initial crack length of $20.3 \mathrm{~mm}$.

The finite element (FE) model was developed using software Abaqus 6.14-3, and was created using element type CPS8R, an 8-node biquadratic plane stress quadrilateral, reduced integration. The SENB model had width, $W$ of $40.0 \mathrm{~mm}$, thickness, $B$, of $19.98 \mathrm{~mm}$, a length of $184 \mathrm{~mm}$ within which the span between the test load points was $160 \mathrm{~mm}$. The initial crack length, $a_{0}$, was $20.304 \mathrm{~mm}$, which was modelled as a $1 \mathrm{~mm}$ wide machined notch, with the last $1.3 \mathrm{~mm}$ being a fatigue pre-crack modeled as a seam in a partition with duplicate overlapping nodes, which are free to move apart as the seam separates on loading. The crack tip was assumed to be straight-fronted to allow for symmetry in the model. Quad elements were used of size $1 \mathrm{~mm}$. Inside a circle region at the crack tip, quad dominatedsweep elements were used, while the rest of the global model used quad-structured elements (Figure 1).The specimen model was loaded under three-point bending with the contact surfaces on the top constrained to movement in the vertical direction, while allowing displacement in the horizontal axis and rotation with respect to the loading points, to simulate the effect of the rollers, and displacement applied at the bottom centre of the specimen to simulate the displacement applied in the threepoints bending test, (Figure 2).

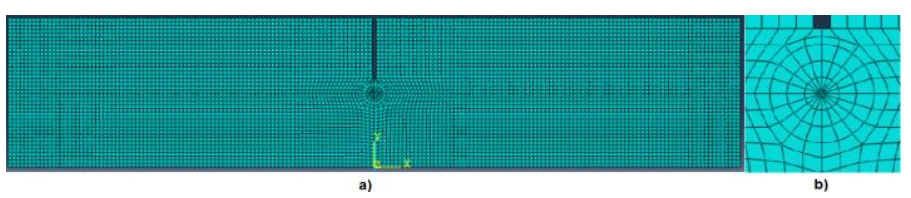

(a)

(b)

FIGURE 1 Global quad mesh of the model, showing the full specimen (a) and a close-up of the crack tip area (b).

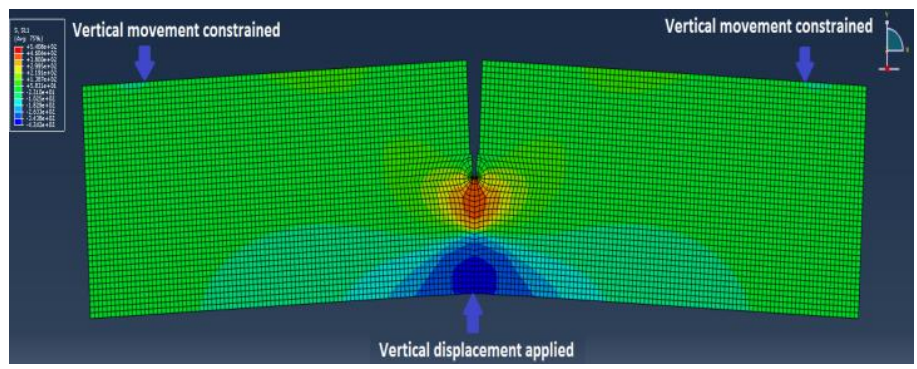

FIGURE 2 SENB specimen model deforming under three-point bending, showing the plastic strain occurring in the specimen 
$\mathrm{J}$ was extracted from the model, both using the contour integral method from the simulation software, and by using the load versus crack mouth displacement data from the model to calculate J using the Standard equation below [5].

$J=\frac{K^{2}\left(1-v^{2}\right)}{E}+\frac{\eta_{p} U_{p}}{B\left(W-a_{0}\right)}$

Where $K$ is the stress intensity factor $\left(\mathrm{N} / \mathrm{mm}^{3 / 2}\right), v$ is Poisson's ratio, $E$ is the elastic modulus $\left(\mathrm{N} / \mathrm{mm}^{2}\right), \eta_{p}$ is a dimensionless function of the specimen geometry, $U_{p}$ is the area under the plastic part of the load versus crack mouth opening displacement curve (Nmm). The method from ASTM E1820 was used, since it gives a formula for $\eta_{\mathrm{p}}$ based on crack mouth opening displacement data directly, rather than requiring a conversion into load line displacement data currently required in ISO 12135 [6]. The displacement data extracted from the model was from the crack mouth displacement, and so the ASTM approach was most relevant, but there is little difference in the values of $\mathbf{J}$ determined using either ASTM or ISO standard equations.

Mesh sensitivity studies were also carried out to ensure sufficient accuracy in the model. The original experiment gave a fracture toughness, J, of $513.05 \mathrm{~N} / \mathrm{mm}$. The FE model assuming plane stress conditions gave an equivalent $\mathrm{J}$ of $513.28 \mathrm{~N} / \mathrm{mm}$ from the standard equation, while the contour integral method directly gave $\mathrm{J}$ of $513.56 \mathrm{~N} / \mathrm{mm}$. Further refinement of the mesh did not change these values significantly, and the model approach was considered to be sufficiently accurate.

\subsection{Modelling a range of weld widths and strength mismatch}

The same modelling approach was then adapted to generate numerical modelling of SENB specimens containing welds, defined in terms of the weld width (2h) and weld strength mismatch $\left(\mathrm{M}_{\mathrm{y}}\right)$. All the specimens were 2D FE simulations of $20 \mathrm{~mm}$ thick Bx2B SENBs. The weld widths were between 3 and 40mm reflecting EBW, GMAW and SAW (discussed in Section 1.2). The overmatch ratio $\left(\mathrm{M}_{\mathrm{y}}\right)$ was from 1 up to 1.9 based on common parent steel and consumable grades. The weld was modeled as a parallel-sided region, centred on the notch, with different (higher) tensile properties (Figure 3). No allowance for a heat affected zone was included in this study.

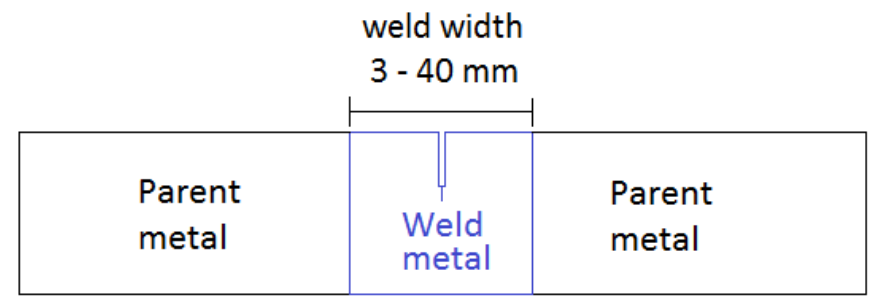

FIGURE 3 Schematic of the approach to modelling SENB specimens containing a welds, where the parent metal and weld metal are given different tensile properties.
A region of weld metal of higher strength around the notch can affect the shape of the plastic zone at the tip of the crack in the specimen. The width of the weld determines the proximity of the lower strength parent metal to influence the crack tip plastic zone. The strength mismatch ratio determines how much difference the effect of the parent metal makes on the crack tip plastic zone. A combination of both mismatch ratio and weld width are needed to describe the way weld metal can affect the crack driving force in pre-cracked fracture toughness test specimens [3].

A series of models were generated based on a weld region with yield strength $520 \mathrm{MPa}$, and parent metal grades of strength $275 \mathrm{MPa}, 355 \mathrm{MPa}, 420 \mathrm{MPa}$ and $520 \mathrm{MPa}$. The stress-strain curves were based on the shape of the experimental data described in section 2.1, but scaled to adjust the yield strength. Therefore the mismatch ratio $\left(\mathrm{M}_{\mathrm{y}}\right)$ range considered in this work was based on a fixed weld metal strength and a range of parent metal grades, giving $\mathrm{M}_{\mathrm{y}}$ between 1 and 1.89. Cases with the same mismatch ratio of 1.2 were considered to show the relative versus absolute effect of $\mathrm{M}_{\mathrm{y}}$, using weld to parent metal strength ratio combinations of 900:750, 420:350 and 300:250.

\section{MODEL RESULTS \& DISCUSSION}

3.1 Effect of weld width and strength mismatch on $\mathrm{J}$, where weld metal yield strength was $520 \mathrm{MPa}$

The results of the numerical models for welds with fixed weld metal strength of 520MPa but a range of mismatch ratios and weld widths are shown in Figures 4 and 5. For any mismatch ratio up to 1.89 , the fracture toughness $\mathbf{J}$ for wider welds are similar to a homogeneous weld material, decreasing as the weld gets narrower, as seen in Figure 4. The difference in fracture toughness from homogeneous weld metal starts being more significant at weld widths between 20 and $30 \mathrm{~mm}$ depending on the level of strength overmatch. In the widest welds, the parent metal is too far from the crack tip for it to affects its behaviour. As the weld gets narrower, $\mathbf{J}$ starts to be affected by the strength of the parent material, reducing the fracture toughness of the specimen. The effect is stronger as the mismatch ratio increases. In the narrowest welds, the fracture toughness value tends towards the value of fracture toughness of the parent metal. This can be seen in the results for mismatch of 1.89 where the effect of the weld on $\mathrm{J}$ plateaus for welds narrower than $10 \mathrm{~mm}$. Here the plastic zone associated with the crack tip is almost completely contained within the parent metal on either side of the high strength narrow weld, and the toughness becomes equivalent to homogeneous parent metal. 


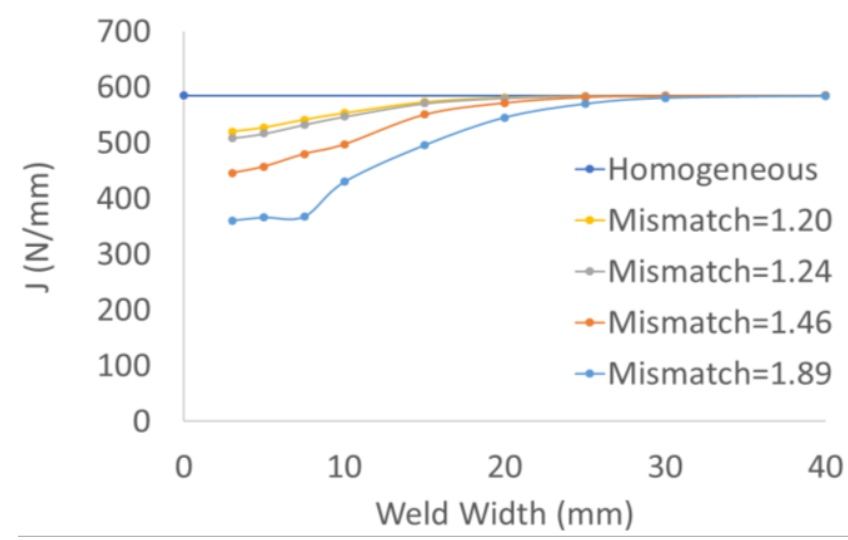

FIGURE 4 Variation of the value of $J$ with the weld width and strength mismatch for specimens weld yield strength of $520 \mathrm{MPa}$.

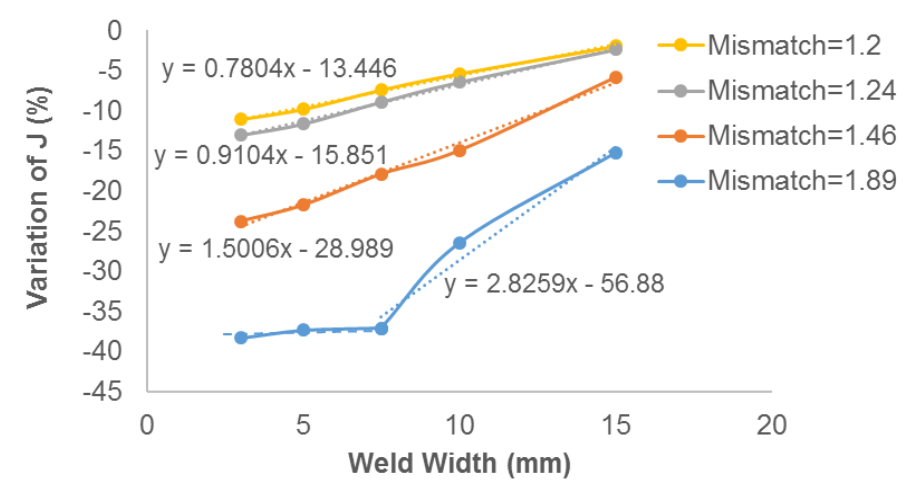

FIGURE 5 Percent difference in the variation of the value of $J$ on welded specimens compared with a homogeneous weld metal.

For welds wider than $30 \mathrm{~mm}$, independent of mismatch ratio, the fracture toughness of the welded specimen remained uniform and equivalent to homogeneous weld metal. For specimens with lower mismatch ratio, $20 \mathrm{~mm}$ was the weld width below which the value of $\mathbf{J}$ started to be affected by weld width. Therefore, it can be said that $20 \mathrm{~mm}$ is the weld width value from where the fracture toughness in terms of $\mathbf{J}$ starts to decrease for over-matched welds. As the thickness of the specimens used for the tests is $20 \mathrm{~mm}$, it might be that this value of the weld width can be related to the thickness of the specimen. To investigate whether this was the case, equivalent models of $40 \mathrm{~mm}$ thick specimens were created, and from these simulations the values of $\mathrm{J}$ obtained for the different cases of weld width were the same as the obtained for specimens of $20 \mathrm{~mm}$ thickness.

This $20 \mathrm{~mm}$ limit could also be based on the ratio of the weld width to the plastic zone size at the crack tip, $r_{p}$, which is itself a function of the fracture toughness, $K$, and yield strength, $\sigma_{Y S}$, [7]:

$r_{p}=\frac{K^{2}}{2 \pi \sigma_{Y S}}$

For steel with yield strength of $520 \mathrm{MPa}$, and assuming a typical linear elastic $K$ of $100 \mathrm{MPa} \vee \mathrm{m}$, the plastic zone radius would be $6 \mathrm{~mm}$. The weld metal fracture toughness will differ from homogenous material once the plastic zone is close to, or intersects the parent metal beyond the weld metal zone.

Plotting the results in terms of percentage reductions (Figure 5) allowed correlation lines to be fitted to predict the effect of weld width and mismatch on J. However, it was first necessary to clarify whether these trends were dependent on the value of weld metal strength.

\subsection{Effect of weld width on $\mathrm{J}$ for a range of weld metal yield strengths, but fixed mismatch ratio of $\mathbf{1 . 2}$}

Three further sets of models of weld metal SENBs were generated on welds with mismatch ratios of 1.2 , but a range of parent metal and weld metal yield strengths. The results are shown in Figure 6.

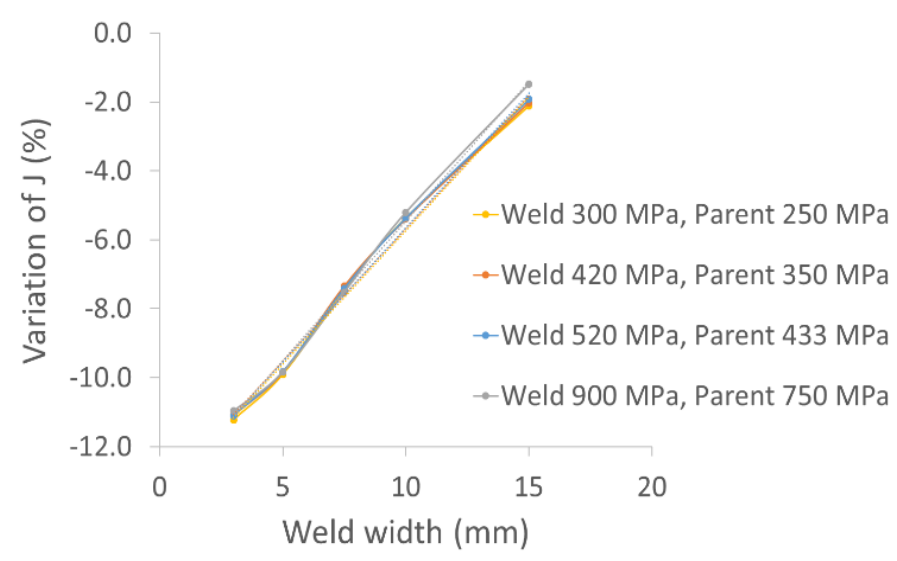

FIGURE 6 Percent difference in the variation of $J$ compared with homogenous weld metal, for a range of welded specimens with a mismatch ratio of 1.2.

The results of these models show that the trend of reduction in $\mathbf{J}$ with weld width $(2 h)$ and overmatch ratio $\left(M_{y}\right)$ is independent of the absolute values of the tensile properties. Based on this finding it was possible to determine empirical formulae to predict how the fracture toughness $\mathrm{J}$ of weld metal centerline (MWCL) notched specimens would compare to the toughness of homogeneous weld metal and parent metal specimens. Compared to homogeneous weld metal, the \% difference in $\mathbf{J}$ for a MWCL notched specimen is:

$\% J=2 h\left(2.7406 M_{y}-2.499\right)-59.76 M_{y}+58.259$

Compared to homogeneous parent metal, the $\%$ difference in $\mathrm{J}$ for a MWCL notched specimen is:

$$
\% J=2 h\left(3.6705 M_{y}-3.4307\right)-11.209 M_{y}+14.562
$$

These formulae were determined based on welds $<20 \mathrm{~mm}$ wide, and for $1<M y<1.5$. For welds $>20 \mathrm{~mm}$ wide the difference in $\mathrm{J}$ is predicted to be less than $1 \%$ of the homogeneous weld metal $\mathrm{J}$. They can be used to help predict how fracture toughness will 
differ in welds compared to homogeneous materials, for example when developing welding procedures for high integrity structures. The results here show that care should be taken for predictions in very narrow welds $(<5 \mathrm{~mm})$ and/or high levels of weld strength overmatching $(>1.5)$, where the accuracy of the linear fitting is reduced.

\section{ACCURACY OF STANDARD $J$ EQUATIONS FOR WELD SPECIMENS}

\subsection{Comparison of $\boldsymbol{J}$ from contour integral and standard equations}

The models here have shown how the presence of welds can affect the fracture toughness that will be determined. However, the second significant question is whether standard methods still determine fracture toughness accurately, or whether narrow, highly overmatched welds are susceptible to errors in the determination of $\mathbf{J}$ when tested using methods developed for homogeneous materials. To quantify this, the values of $\mathrm{J}$ extracted from the weld specimen models from the contour integral method were compared to values of $\mathrm{J}$ based on loadCMOD traces and calculated using the standard method, Equation 1. Comparing the percentage difference between the two gives an indication of the accuracy of the method given in the standard (using the area under the load versus displacement trace measured during the test on the specimen to determine $\mathrm{J}$ ), in comparison to the actual $\mathbf{J}$ at the crack tip, determined from the model's contour integral method. These percentage differences are plotted against weld width for a range of weld strength mismatch ratios in Figure 7. The results showed that for all the mismatch ratios analysed here, apart from $\mathrm{M}_{\mathrm{y}}$ of 1.89 , the value of $\mathrm{J}$ from the standard method differed by only up to $6 \%$ from the contour integral $\mathrm{J}$, and was within $5 \%$ for most cases.

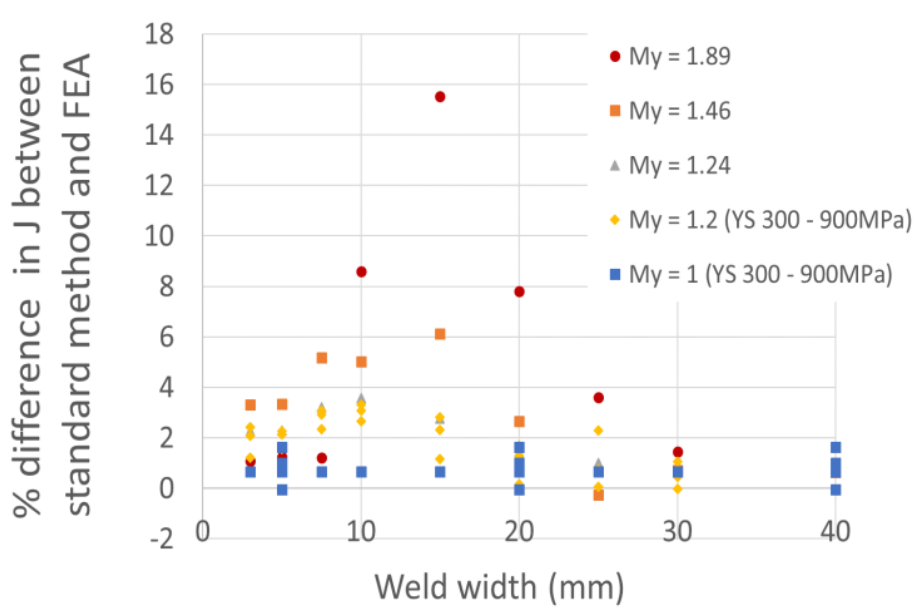

FIGURE 7 Percent difference in the value of $\mathbf{J}$ determined using standard equations, and extracted directly from FEA, for a range of welded widths and strength mismatch ratios.

\subsection{Possible implications for BS EN ISO 15653}

The results suggest that that standard BS EN ISO 15653 is currently over-conservative by limiting the mismatch ratio to 1.25 for a valid $\mathrm{J}$, and that is would be appropriate for the standard to permit mismatch ratios of up to 1.5 for valid $\mathrm{J}$ and CTOD to be determined to the standard. The clauses states that the error in CTOD and $\mathrm{J}$ if mismatch is within the limit of the standard is up to $10 \%$. This seems to be a generous error margin, and the standard method can be considered to be more accurate that this is the majority of cases.

The results here also agree that for mismatch in excess of the standard limits, the value of $\mathrm{J}$ will be over-estimated, as shown in Figure 7 in the data for $\mathrm{M}_{\mathrm{y}}$ of 1.89.

A limited investigation of CTOD was made by extracting values of crack tip displacement at a crack depth of $\mathrm{a}_{0}$ from some of the models, and comparing it to the prediction of CTOD from standard equations based on the crack mouth displacement and an assumed rigid rotation of the specimen about a plastic hinge in the ligament. The results showed that the typical error in CTOD values is closer to $10 \%$ for specimens within the mismatch range given in BS EN ISO 15653, and therefore no changes to the current CTOD clauses in BS EN ISO 15653 seem necessary.

There is a limit given in BS EN ISO 15653 on the weld width to specimen ligament ratio, $2 \mathrm{~h} /\left(\mathrm{W}-\mathrm{a}_{0}\right)$, which must exceed a value of 0.2 . In order to visualize the implications of this limit on different weld and specimen geometries, Figure 8 plots the weld width to specimen ligament ratio against weld width for a range of specimen sizes, as indicated by the ligament length. For example a specimen with a ligament $\left(\mathrm{W}-\mathrm{a}_{0}\right)$ of $10 \mathrm{~mm}$ would be equivalent to a $10 \mathrm{~mm}$ x $20 \mathrm{~mm} \mathrm{~B} \times 2 \mathrm{~B}$ SENB specimen, or a $20 \mathrm{~mm} \times 20 \mathrm{~mm} B \times B$ SENB specimen, notched to an $\mathrm{a}_{0} / \mathrm{W}$ ratio of 0.5 .

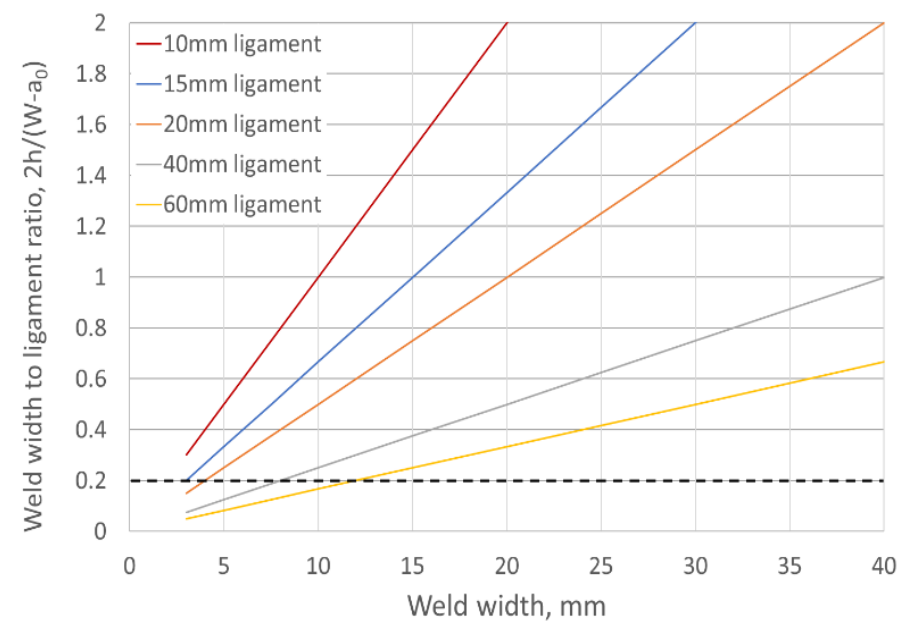

FIGURE 8 Implications of BS EN ISO 15653 weld width to ligament ratio limit of 0.2 (indicated by the dotted line) for a range of weld widths and specimen $(\mathrm{W}$-a0) ligaments.

Figure 8 shows that this limitation of $2 h /\left(w-a_{0}\right)>0.2$ will only affect specimens extracted from thicker specimens 
containing narrow welds. For instance, a narrow gap GMAW weld of width $10 \mathrm{~mm}$ in a Bx2B specimen $60 \mathrm{~mm} \times 120 \mathrm{~mm}$ in size will only just meet this requirement. However, this limit might also restrict the application of the standard to power-beam welds, such as electron beam welds in material only $20 \mathrm{~mm}$ thick or more, whereas the numerical models presented in this work show that welds narrower than $10 \mathrm{~mm}$ are characterized just as accurately as welds between 10 and $20 \mathrm{~mm}$ thick in material of $20 \mathrm{~mm}$ to $40 \mathrm{~mm}$ thickness.

The results from this research could be used to provide further guidance to those performing fracture toughness tests on specimens notched into weld metals. In particular, the formulae given in Equations 3 and 4 could help identify suitable weld joint designs to vary the expected weld width, $2 \mathrm{~h}$, or to help select suitable weld consumables to control the strength mismatch, $\mathrm{M}_{\mathrm{y}}$, in order to minimise the influence of the weld joint on the fracture toughness. It is unlikely that very thick weld joints exceeding $20 \mathrm{~mm}$ will be selected simply to reduce the effect on fracture toughness, since larger weld grooves require more weld metal, longer welding times and are more costly. There will be a commercial balance between productivity and the welding processes available, alongside the considerations discussed here.

The limit of $20 \mathrm{~mm}$ for the weld width that shows the effect of strength mismatch could be a consequence of absolute specimen thickness (here B was 20mm). However, some validation models on $40 \mathrm{~mm}$ thick specimens also showed the same $20 \mathrm{~mm}$ limit on the weld width effect. This $20 \mathrm{~mm}$ dimension could be influenced by the plastic zone size at the crack tip discussed in Section 3.1. For steels with yield strengths from 250 to $520 \mathrm{MPa}$, and assuming a linear elastic $\mathrm{K}$ of $100 \mathrm{MPa} \sqrt{\mathrm{m}}$, the plastic zone radius is of the order of $5-25 \mathrm{~mm}$, and would affect the weld metal fracture toughness once a significant part of the plastic zone intersected the parent metal beyond the weld metal zone. $20 \mathrm{~mm}$ does not seem to be a hard limit, and further investigation might be needed to define this limit more accurately, possibly in terms of yield strength, ligament size, or plastic zone radius.

\section{CONCLUSIONS \& RECOMMENDATIONS}

From the work presented here, the following conclusions have been made.

- For any weld strength overmatch ratio up to 1.9 , the fracture toughness, J, for welds wider than around $20 \mathrm{~mm}$ is within $10 \%$ of that from a homogeneous weld metal specimen.

- The value of $\mathrm{J}$ in weld metal centerline specimens decreases compared to homogeneous weld metal as the weld gets narrower.

- The trend for the reduction of toughness, J, with weld width was the same for range of parent grades, each with the same mismmatch, $\mathrm{My}=1.2$

- Compared to homogeneous weld metal, the $\%$ difference in $\mathrm{J}$ for a MWCL notched specimen is:

$\% J=2 h\left(2.7406 M_{y}-2.499\right)-59.76 M_{y}+58.259$
- Compared to homogeneous parent metal, the \% difference in $\mathrm{J}$ for a MWCL notched specimen is:

$$
\% J=2 h\left(3.6705 M_{y}-3.4307\right)-11.209 M_{y}+14.562
$$

- The difference between $\mathrm{J}$ extracted from FEA contour integral method and using standard equations was less than $5 \%$ in most cases where the mismatch was within the standard limits of 1.5

- For welds narrower than $20 \mathrm{~mm}$ and with a mismatch up to 1.9 , the error was up to a $16 \%$ over-estimation of $\mathrm{J}$.

- It is recommended to extend the permitted weld strength mismatch ratio given in BS EN ISO 15653 to 1.5 for $\mathrm{J}$ as well as CTOD determination.

\section{ACKNOWLEDGMENTS}

The research presented here was carried out as a Masters research project with Brunel University and funded by the National Structural Integrity Research Centre (NSIRC) at TWI, Cambridge.

\section{REFERENCES}

[1] BS EN ISO 15653:2010 'Metallic materials. Method of test for the determination of quasistatic fracture toughness of welds'. [2] Henryk Pisarski, "The effect of yield strength mismatch on CTOD and J estimation procedures for weld metal fracture toughness determination," in OMAE, Copenhagen, 1995.

[3] G. H. B. Donato, R. Magnabosco and C. Ruggieri, "Effects of weld strength mismatch on $\mathrm{J}$ and CTOD estimation procedure for SE(B) specimens," Springer, 2009.

[4] Lincoln Welding Consumables Catalog 2017.

[5] ASTM E1820. Standard Test Method for Measurement of Fracture Toughness, 2017: ASTM International.

[6] ISO 12135. Metallic Materials - Unified method of test for the determination of quasistatic fracture toughness, ISO , 2016.

[7] K Macdonald, 'Fracture and Fatigue of Welded Joints and Structures' Woodhead Publishing, 2011. 